\title{
The Effect of Estrogen and Progesterone Receptor Status on the Prognosis of Endometrioid Type Endometrial Cancer: Retrospective Study
}

\author{
[] İrem ALYAZICI KÜÇÜKYILDIZa, ${ }^{(0)}$ Ali YANIK ${ }^{\mathrm{a}}$

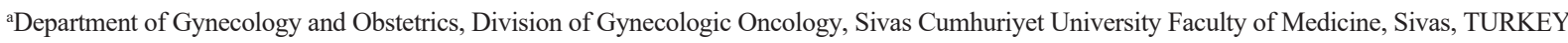

\begin{abstract}
Objective: Endometrioid-type endometrial cancer (EC) is the most common histological type of EC, and generally has good survival if diagnosed during the early stages. While tumour grade, stage and lymph node invasion are known to affect survival in these patients, the prognostic significance of steroid receptor status remains unclear. The present study aimed to determine the effect of estrogen and progesterone receptor (ER and PR, respectively) status and its relationship with other prognostic factors in endometrioid-type EC. Material and Methods: Data from 152 patients who underwent surgery at the same centre between 2009 and 2019 were retrospectively evaluated. Histological characteristics of tumours were determined using the original pathology reports, and stage, grade and lymph node involvement of tumours were compared with ER and PR status. The relationship between ER and PR status and preoperative serum cancer antigen 125 and albumin levels were also investigated. Results: When the results of our study were examined, it was revealed that 114 patients had Grade I tumor and 118 had International Federation of Gynecology and Obstetrics Stage I tumor and 34 patients had ER and PR negativity. In our study, a dependence was found between both ER and PR status and pelvic lymph node involvement. It was found that the possibility of pelvic lymph node involvement increases in both hormone receptor negativity. Conclusion: This study reports that the patients with pelvic lymph node involvement, which is a prognostic factor in EC, may experience more frequent ER and PR negativity. However, its effects on survival remain unclear.
\end{abstract}

Keywords: Endometrial cancer; survival; estrogen receptor; progesterone receptor

Among gynecological cancers, endometrial cancer (EC) is the most common in developed countries and the second most common in the world. According to the GLOBOCAN 2018 database, which is a project of the International Agency for Research on Cancer that provides estimates according to cancer site and gender for each country and worldwide, nearly 380,000 new EC cases are reported worldwide each year. ${ }^{1}$

ECs are broadly classified into two major types based on their clinicopathological features. ${ }^{2}$ Type 1 cancers are low-grade endometrioid ECs [International Federation of Gynecology and Obstetrics (FIGO) Grades I and II], whereas Type 2 cancers include FIGO Grade III endometrioid ECs and non-endometrioid histology (serous, clear cell, mixed cell and undifferentiated).
Endometrioid histology is the most common type of EC, accounting for $75 \%$ to $80 \%$ of cases, and is predominantly comprised of low-grade endometrioid ECs. ${ }^{3}$ Endometrioid-type EC develops due to prolonged exposure to endogenous or exogenous estrogen, unopposed by progesterone, and is mostly seen in females with a high body mass index. An indication of the relationship of these cancers with estrogen is the high rate of estrogen receptor (ER) and progesterone receptor (PR) expression. ${ }^{4}$ These tumors are often low-grade and prognosis is generally good when caught at an early stage. ${ }^{5}$ However, Type $2 \mathrm{EC}$ is a serous type that usually develops from the atrophic endometrium, independent of estrogen. $\mathrm{Pa}$ tients with this type of tumor have low serum estrogen levels and low ER and PR expression. ${ }^{4}$ These

\footnotetext{
Correspondence: İrem ALYAZICI KÜÇÜKYILDIZ

Department of Gynecology and Obstetrics, Division of Gynecologic Oncology, Sivas Cumhuriyet University Faculty of Medicine, Sivas, TURKEY E-mail: iremalyazici@hotmail.com

Peer review under responsibility of Journal of Clinical Obstetrics \& Gynecology.

Received: 27 Jan 2021

Received in revised form: 27 May 2021

Accepted: 23 Aug 2021

Available online: 31 Aug 2021

2619-9467 / Copyright @ 2021 by Türkiye Klinikleri. This is an open

access article under the CC BY-NC-ND license (http://creativecommons.org/licenses/by-nc-nd/4.0/).
} 
tumors tend to be diagnosed at advanced stages and are associated with poor prognosis.

Many studies have identified prognostic factors, such as age, histological type, grade and lymphovascular space invasion, for EC. ${ }^{6,7}$ Other than conventional demographic or clinicopathological features, biological molecules have been suggested as prognostic biomarkers in EC, such as preoperative albumin levels, P53, KRAS, PTEN, ER, PR and human epidermal growth factor receptor $2.8,9$

The present study investigated whether ER and PR positivity was an independent prognostic factor in patients with endometrioid-type EC and examined its relationship with other known prognostic factors.

\section{MATERIAL AND METHODS}

Clinical and laboratory data were retrospectively collected from the hospital archive from 152 patients with endometrioid-type EC who were treated between 2009 and 2019 at the same center. This study was conducted according to the principles stated in the Declaration of Helsinki. It was approved by the Sivas Cumhuriyet University Ethics Committee [registry no: $2020-05 / 17$, date: 20.5 .2020$]$. Informed constent was not required due to retrospective design of the study.

Histological tumor characteristics were abstracted from the original pathology reports. Only patients with endometrioid type EC histology were included in the study, and patients with non-endometrioid type EC histology were excluded from the study. Endometrioid type EC diagnosis of the patients was made by histopathological examinations of hematoxylin-eosin stained preparations. Tumor stages were measured by using the FIGO system (I, II, III or IV) according to the pathological reports. Cases were categorized as Grade I (well-differentiated), Grade II (moderately differentiated) and Grade III (poorly differentiated) adenocarcinomas according to the World Health Organization criteria. While total abdominal hysterectomy, bilateral salpingo-oophorectomy were applied to all patients, whereas lymphadenectomy was not performed in 21 patients with FIGO Stage I and low grade patients.

Lymph node positivity and ER and PR status were determined according to the patients' pathology results. ER and PR status of the tumors were categorized as follows: receptor negativity, $<50 \%$ receptor positivity and $>\% 50$ receptor positivity.

Patients' serum cancer antigen 125 (CA125) levels and routine blood test results were examined. Preoperative serum albumin levels were available for 112 patients, and 147 patients had serum CA125 results. Serum albumin levels were classified as either low $(<3.5 \mathrm{~g} / \mathrm{dL})$ or normal $(3.5-5 \mathrm{~g} / \mathrm{dL})$ and CA125 levels were classified as either normal $(<35 \mathrm{U} / \mathrm{mL})$ or high ( $\geq 35 \mathrm{U} / \mathrm{mL}$ ).

Data were analyzed using SPSS for Windows version 22.0. Categorical variables were compared using chi-square (homogeneity and independence chi-square test) and cross-tabulation tests, as appropriate. Kaplan-Meier analyses were used to assess survival. Significance was defined using levels of $\mathrm{p}<0.05$ and $95 \%$ confidence intervals (CIs).

\section{RESULTS}

\section{PATIENT CHARACTERISTICS}

The present study included 152 patients who underwent surgery due to EC of the uterine corpus in the same center. All patients underwent total abdominal hysterectomy bilateral salpingo-oophorectomy, and bilateral pelvic para aortic lymph node dissection was also performed in 131 patients. The median age of the patients was 57 (26-83) years.

The mean preoperative albumin value of $112 \mathrm{pa}$ tients was 4.18 (2.5-4.9) g/dL and the mean serum CA125 level of 147 patients was $51(3-1,924) \mathrm{g} / \mathrm{dL}$. Among the 15 patients who died, 10 deaths were ECrelated.

\section{TUMOR PATHOLOGY}

Evaluation of the pathology results revealed that 114 (75\%) patients had Grade I and 118 had FIGO Stage I (77.6\%) disease, 15 (9.9\%) patients had pelvic lymph node positivity and 34 (22.4\%) patients had ER and PR negativity (Table 1). When the ER and PR positive groups were evaluated according to positivity receptor level, $11(7.2 \%)$ patients had $<50 \%$ positivity rate in the ER and PR groups (Table 1). 


\begin{tabular}{|c|c|c|}
\hline \multicolumn{3}{|c|}{ TABLE 1: Distribution of parameters. } \\
\hline & $\mathrm{n}$ & $\%$ \\
\hline \multicolumn{3}{|l|}{ Tumor grade } \\
\hline Grade I & 114 & 75 \\
\hline Grade II & 24 & 15.8 \\
\hline Grade III & 13 & 8.6 \\
\hline \multicolumn{3}{|l|}{ FIGO tumor stage } \\
\hline FIGO I & 118 & 77.6 \\
\hline FIGO ॥ & 13 & 8.6 \\
\hline FIGO III & 17 & 11.2 \\
\hline FIGO IV & 4 & 2.6 \\
\hline \multicolumn{3}{|l|}{ Pelvic lymph node status } \\
\hline Positive & 15 & 9.9 \\
\hline Negative & 116 & 76.3 \\
\hline \multicolumn{3}{|l|}{ ER status } \\
\hline Receptor negativity & 34 & 22.4 \\
\hline Receptor positivity <50\% & 11 & 7.2 \\
\hline Receptor positivity $\geq 50 \%$ & 107 & 70.4 \\
\hline \multicolumn{3}{|l|}{ PR status } \\
\hline Receptor negativity & 34 & 22.4 \\
\hline Receptor positivity < $50 \%$ & 11 & 7.2 \\
\hline Receptor positivity $\geq 50 \%$ & 107 & 70.4 \\
\hline \multicolumn{3}{|l|}{ CA125 level } \\
\hline Normal (<35 U/mL) & 112 & 73.7 \\
\hline High ( $\geq 35 \mathrm{U} / \mathrm{mL}$ ) & 35 & 23 \\
\hline \multicolumn{3}{|c|}{ Serum preoperative albumin level } \\
\hline Low $(<3.5 \mathrm{~g} / \mathrm{dL})$ & 11 & 7.2 \\
\hline Normal (3.5-5 g/dL) & 101 & 66.4 \\
\hline \multicolumn{3}{|l|}{ Disease-related exitus } \\
\hline Absent & 137 & 90.1 \\
\hline Present & 10 & 6.6 \\
\hline
\end{tabular}

ER: Estrogen receptor; PR: Progesterone receptor; FIGO: International Federation of Gynecology and Obstetrics; CA125: Cancer antigen.

\section{ER STATUS}

In the statistical analysis results of our study, dependence was found between the ER status and pelvic lymph node involvement. It was found that the possibility of pelvic lymph node involvement increased in ER negativity (Table 2).

No dependence was found between ER status and tumor grade, tumor stage serum CA125 levels and preoperative albumin levels (Table 2).

When the ER status of the patients without pelvic lymph node involvement was examined, it was found that $\geq 50 \%$ positivity group was more common.
When the ER status of the patients with Grade I tumor and Grade II tumor were examined separately, it was found that $\geq 50 \%$ positivity group was more common in both groups (Table 2).

When ER status was evaluated according to the $<50 \%$ positivity, $\geq 50 \%$ positivity and receptor negativity groups, the average life expectancy of patients with $<50 \%$ positivity was $98.0 \pm 11.8$ months $(95 \%$ CI, 74.7-121.3). The average life expectancy of patients with ER $\geq 50 \%$ positivity was $98.8 \pm 2.27$ months (95\% CI, 94.33-103.27), whereas that of patients with ER negativity was $100.69 \pm 4.1$ months (95\% CI, 92.6-108.7). The average life expectancy for all patients was $108.59 \pm 2.58$ months (95\% CI, 103.53-113.65). However, this difference was not significant when both groups were compared (Figure 1).

\section{PR STATUS}

In the results of our study, dependence was found between the PR status and pelvic lymph node involvement, tumor grade. It was found that the possibility of pelvic lymph node involvement increased in PR negativity (Table 3).

It was also found that the probability of a Grade I tumor increased in the PR negativity group and in the $\geq 50 \%$ positivity group (Table 3 ).

No dependence was found between PR status and tumor stage serum CA125 levels and preoperative albumin levels (Table 3 ).

When the PR status of the patients without pelvic lymph node involvement was examined, it was found that $\geq 50 \%$ positivity group was more common (Table 3).

When the progesterone receptor status was examined in patients with Grade I tumors, it was observed that the receptor negative group and $\geq 50 \%$ positivity group were more frequent.

When PR status was evaluated as $<50 \%$ positivity, $\geq 50 \%$ positivity and receptor negativity groups, the average life expectancy of patients with $<50 \%$ positivity was $94.3 \pm 13.8$ months (95\% CI, 67.3121.4). The average life expectancy of patients with $\mathrm{PR} \geq 50 \%$ positivity was $99.8 \pm 2.06$ months $(95 \% \mathrm{CI}$, 95.78-103.86) whereas that of patients with PR neg- 


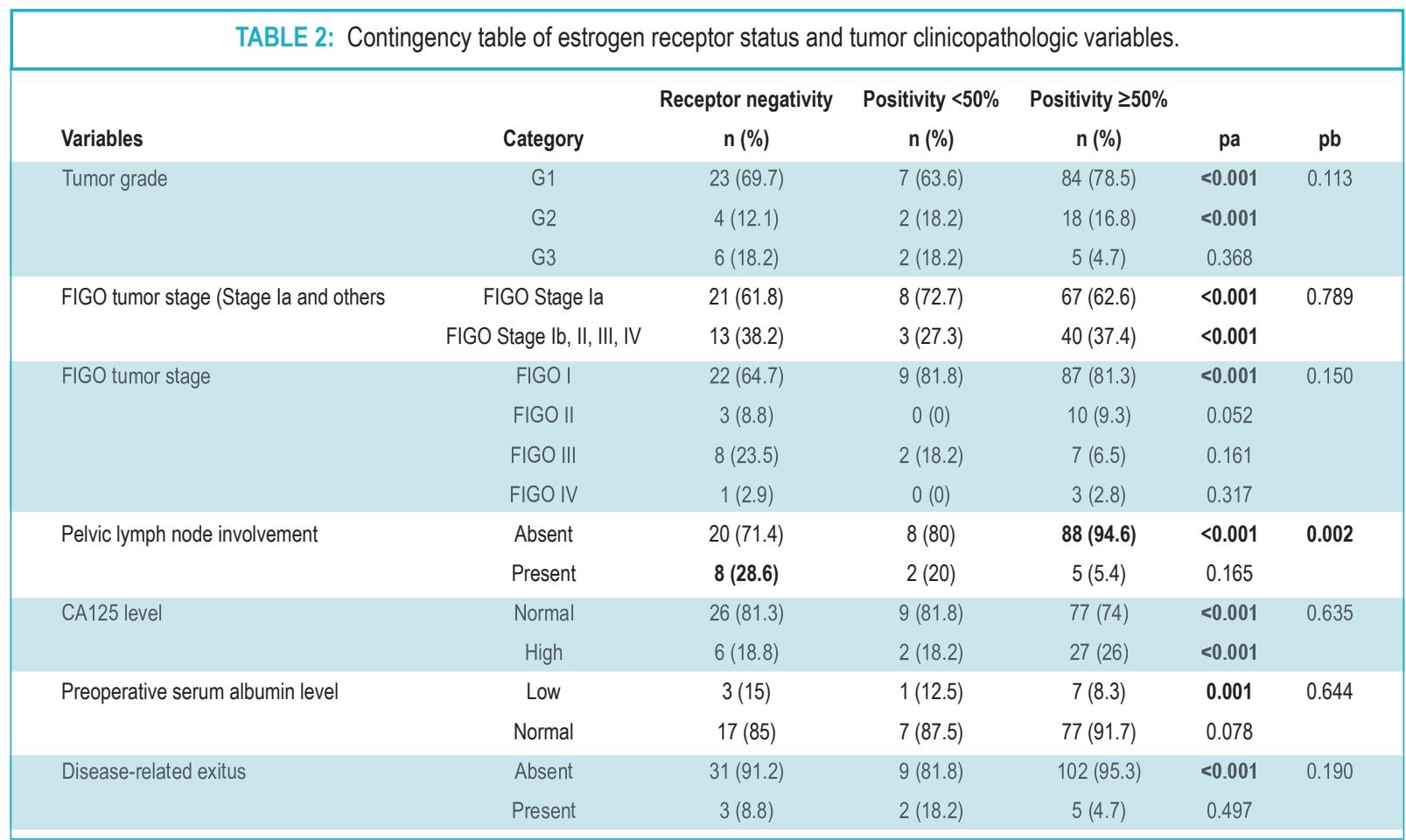

Chi-square test; aHomojenity chi-square test; ${ }^{\prime}$ Independence chi-square test; $p<0.05$ significant; FIGO: International Federation of Gynecology and Obstetrics; CA125: Cancer antigen.

ativity was $97.86 \pm 4.82$ months $(95 \% \mathrm{CI}, 88.40-$ 107.32). The average life expectancy of all patients was $108.59 \pm 2.58$ months (95\% CI, 103.53-113.65). This difference was not significant when both groups were compared (Figure 2).

\section{DISCUSSION}

Type 1 EC generally occurs due to high estrogen levels and refers to hormone receptor-positive tumors with low-grade endometrioid histology that are often associated with good prognosis. On the contrary, Type 2 EC usually develops from atrophic endometrium, independent of estrogen, and refers to high-grade, hormone receptor-negative tumors with a non-endometrioid histology that are associated with poorer prognosis than Type 1 tumors. ${ }^{4,5,10}$

Estrogen promotes the growth and proliferation of the endometrium via ERs, and progesterone functions as an estrogen antagonist as it inhibits endometrial maturation and proliferation. ${ }^{11,12}$ Therefore, hormone receptor status may play an important prognostic role in the treatment and management of EC.

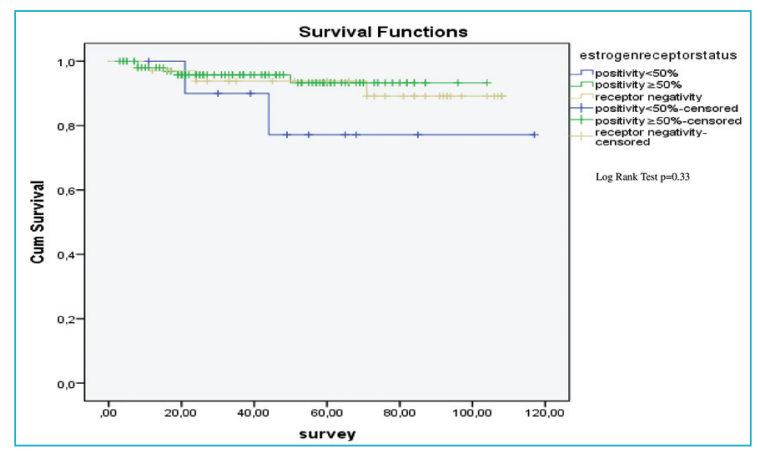

FIGURE 1: Graphical presentation of the effect of estrogen receptor status on overall survival by Kaplan-Meier analysis.

ERs and PRs have recently been investigated as biological molecules in relation to outcome and prognosis of female cancers, such as breast cancer, ovarian cancer and EC. ${ }^{13,14}$ In a meta-analysis examining the relationship between ovarian cancer and hormone receptor, elevated PR levels predicted favorable survival. ${ }^{13}$ On the other hand, ER and PR-negative breast tumors are unlikely to respond to hormone therapy. In addition, the absence of ER in primary breast tumors is considered an important independent prognostic factor for higher recurrence rate and shorter survival. ${ }^{15}$ 


\begin{tabular}{|c|c|c|c|c|c|c|}
\hline Variables & Category & $\begin{array}{l}\text { Receptor negativity } \\
\mathrm{n}(\%)\end{array}$ & $\begin{array}{c}\text { Positivity }<50 \% \\
\text { n (\%) }\end{array}$ & $\begin{array}{c}\text { Positivity } \geq 50 \% \\
n(\%)\end{array}$ & $\mathrm{p}^{\mathrm{a}}$ & $\mathrm{p}^{\mathrm{b}}$ \\
\hline \multirow[t]{3}{*}{ Tumor grade } & G1 & $23(69.7)$ & $4(36.4)$ & $87(81.3)$ & $<0.001$ & 0.010 \\
\hline & G2 & $5(15.2)$ & $5(45.5)$ & $14(13.1)$ & 0.034 & \\
\hline & G3 & $5(15.2)$ & $2(18.2)$ & $6(5.6)$ & 0.368 & \\
\hline \multirow[t]{2}{*}{ FIGO tumor stage (Stage la and others } & FIGO Stage la & $20(58.8)$ & $7(63.6)$ & $69(64.5)$ & $<0.001$ & 0.837 \\
\hline & FIGO Stage Ib, II, III, IV & $14(41.2)$ & $4(36.4)$ & $38(35.5)$ & $<0.001$ & \\
\hline \multirow[t]{4}{*}{ FIGO tumor stage } & FIGO I & $21(61.8)$ & $9(81.8)$ & $88(82.2)$ & $<0.001$ & 0.114 \\
\hline & FIGO II & $4(11.8)$ & $0(0)$ & $9(8.4)$ & 0.166 & \\
\hline & FIGO III & $8(23.5)$ & $2(18.2)$ & $7(6.5)$ & 0.161 & \\
\hline & FIGO IV & $1(2.9)$ & $0(0)$ & $3(2.8)$ & 0.317 & \\
\hline \multirow[t]{2}{*}{ Pelvic lymph node involvement } & Absent & $20(71.4)$ & $8(80)$ & $88(94.6)$ & $<0.001$ & 0.002 \\
\hline & Present & $8(28.6)$ & $2(20)$ & $5(5.4)$ & 0.165 & \\
\hline \multirow[t]{2}{*}{ CA125 level } & Normal & $25(78.1)$ & $9(81.8)$ & $78(75)$ & $<0.001$ & 0.844 \\
\hline & High & $7(21.9)$ & $2(18.2)$ & $26(25)$ & $<0.001$ & \\
\hline \multirow[t]{2}{*}{ Preoperative serum albumin level } & Low & $3(14.3)$ & $0(0)$ & $8(9.6)$ & $<0.001$ & 0.510 \\
\hline & Normal & $18(85.7)$ & $8(100)$ & $75(90.4)$ & 0.132 & \\
\hline \multirow[t]{2}{*}{ Disease-related exitus } & Absent & $30(88.2)$ & $9(81.8)$ & $103(96.3)$ & $<0.001$ & 0.071 \\
\hline & Present & $4(11.8)$ & 2 (18.2) & $4(3.7)$ & 0.670 & \\
\hline
\end{tabular}

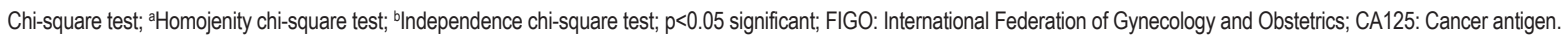

Previous studies have shown that ER and PR are more likely to be positive in well-differentiated tumors. Furthermore, the probability of ER and PR positivity decreases as tumor grade and FIGO stage increase. ${ }^{16,17}$ In another study, a statistically significant relationship was found between tumor grade and PR in EC cases, whereas no statistically significant relationship was found between ER and grade. ${ }^{18}$ Our results are compatible with these two studies. Both ER and PR receptor $\geq 50 \%$ positivity were higher in low-grade cases.

Lymph node involvement is an advanced tumor indicator. In our study, ER and PR negativity was significantly higher in cases with lymph node involvement. While the presence of ER and PR may be associated with favorable outcomes in the majority of Type 1 tumors, its prognostic significance remains unclear. ${ }^{19}$ In many studies, the presence of ER and PR was associated with a more favorable prognosis and better disease-free survival..$^{16,20}$ On the other hand, other studies found no relationship between ER and PR presence and survival. ${ }^{18}$ In the present study, no statistically significant relationship was found between ER and PR presence and survival. It was reported that for EC

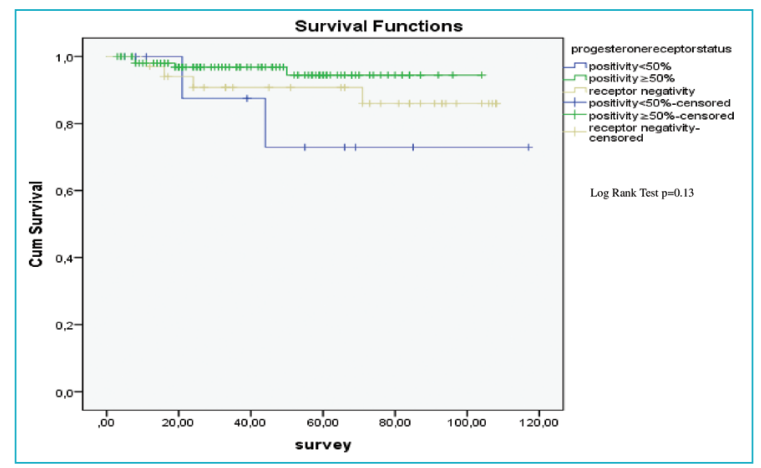

FIGURE 2: Graphical presentation of the effect of progesterone receptor status on overall survival by Kaplan-Meier analysis.

cases, PR status may have greater significance in predicting prognosis than ER status alone. ${ }^{20}$

Recent studies have indicated that preoperative serum CA125 and albumin levels may have prognostic significance in patients with EC. Low serum albumin and high CA125 levels preoperatively were associated with poor survival. ${ }^{21,22}$ In the present study, no statistically significant relationship was found between ER and PR status and preoperative serum CA125 and albumin levels. 
The strengths of our study are that we only evaluated endometrioid type EC cases that underwent surgery at a single center and whose pathology was evaluated by the same team. Furthermore, the number of cases in the present study was high compared with that of other studies. In addition to the prognostic factors examined in previous studies, ER and PR status were also compared with other possible EC prognostic factors.

In addition to comparing the presence and absence of ER and PR, the receptor-positive groups were compared with each other as well as their receptor positivity rates. There have been no previous studies comparing ER and PR positivity levels.

The limitations of the present study include its retrospective design and statistical limitations as a result of the low death rates due to the good prognosis in Stage I, low number of advanced stage patients and short follow-up period.

\section{CONCLUSION}

In conclusion, in our study, a dependence was found between the ER and PR status and pelvic lymph node involvement, which is a prognostic factor in EC. It has been reported that the ER and PR negativity may be encountered more frequently in patients with pelvic lymph node involvement. However, there was no dependence between hormone receptor status and tumor stage, serum CA125 levels or serum preoperative albumin levels, which are used as prognostic factors for EC. Moreover, no statistically significant relationship was found between ER and PR status and survival. The prognostic effect of ER and PR status in $\mathrm{EC}$ is keeping the background and further investigation is needed.

\section{Source of Finance}

During this study, no financial or spiritual support was received neither from any pharmaceutical company that has a direct connection with the research subject, nor from a company that provides or produces medical instruments and materials which may negatively affect the evaluation process of this study.

\section{Conflict of Interest}

No conflicts of interest between the authors and / or family members of the scientific and medical committee members or members of the potential conflicts of interest, counseling, expertise, working conditions, share holding and similar situations in any firm.

\section{Authorship Contributions}

Idea/Concept: Irem Alyazıcı Küçükyıldız; Design: İrem Alyazıcı Küçükyıldız; Control/Supervision: Ali Yanık; Data Collection and/or Processing: Irem Alyazıcı Kü̧̈ükyıldız, Ali Yanık; Analysis and/or Interpretation: Irem Alyazıcı Küçükylldız; Literature Review: İrem Alyazıcı Küçükyıldız; Writing the Article: Irrem Alyazıcı Küçükyıldız; Critical Review: Irem Alyazıcı Küçükyıldız, Ali Yanık; References and Fundings: Ali Yanık; Materials: Irem Alyazıcı Küçükyıldız.

\section{REFERENCES}

1. Bray F, Ferlay J, Soerjomataram I,Siegel RL, Torre LA, Jemal A. Global cancer statistics 2018: GLOBOCAN estimates of incidenceand mortality worldwide for 36 cancers in 185 countries. CA Cancer J Clin.2018;68(6):394424. Erratum in: CA Cancer J Clin. 2020;70(4): 313. [Crossref] [Pubmed]

2. Bokhman JV. Two pathogenetic typesof endometrial carcinoma. Gynecol Oncol. 1983; 15(1):10-7. [Crossref] [Pubmed]

3. Kurman RJ, Carcangiu ML, Herrington CS. WHO Classification of Tumours ofFemale Reproductive Organs. 4th ed. Lyon: International Agency for Research on Cancer; 2014.

4. Lax SF. Pathology of endometrialcarcinoma. In: Ellenson LH, ed. Molecular Genetics of En- dometrial Carcinoma. 1st ed. Cham:Springer; 2017. p.75-96. [Crossref] [Pubmed]

5. Amant F, Moerman P, Neven P,Timmerman D, Van Limbergen E, Vergote I. Endometrial cancer. Lancet. 2005;366(9484):491-505. [Crossref] [Pubmed]

6. Kosary CL. FIGO stage, histology,histologic grade, age and race as prognostic factors in determining survival for cancers ofthe female gynecological system: an analysis of 1973-87 SEER cases of cancers of theendometrium, cervix, ovary, vulva, and vagina. Semin Surg Oncol. 1994;10(1):31-46. [Crossref] [Pubmed]

7. Schink JC, Rademaker AW, MillerDS, Lurain JR. Tumor size in endometrial cancer. Cancer. 1991;67(11):2791-4. [Crossref] [Pubmed]
8. Seebacher V, Grimm C, ReinthallerA, Heinze $G$, Tempfer $C$, Hefler $L$, et al. The value of serum albumin as a novel independentmarker for prognosis in patients with endometrial cancer. Eur J Obstet Gynecol Reprod Biol. 2013;171(1):101-6. [Crossref] [Pubmed]

9. Salvesen HB, Haldorsen IS, TrovikJ. Markers for individualised therapy in endometrial carcinoma. Lancet Oncol.2012;13(8):e353-61. [Crossref] [Pubmed]

10. Budak E, Solakoglu Kahraman D,Budak A, Yanarateş A, Inan AH, Kanmaz AG, et al. The prognostic significance of serum CA125 levels with ER, PR, P53 and Ki-67 expression in endometrial carcinomas. Ginekol Pol. 2019;90(12):675-83. [Crossref] [Pubmed] 
11. Liu R, Dong JT, Chen C. Role ofKLF5 in hormonal signaling and breast cancer development. Vitam Horm. 2013;93:213-25. [Crossref] [Pubmed]

12. Ito $\mathrm{K}$, Utsunomiya $\mathrm{H}$, Yaegashi $\mathrm{N}$,Sasano $\mathrm{H}$. Biological roles of estrogen and progesterone in human endometrial carcinoma--newdevelopments in potential endocrine therapy for endometrial cancer. Endocr J. 2007;54(5): 667-79. [Crossref] [Pubmed]

13. Zhao $D$, Zhang F, Zhang W, He J,Zhao $Y$, Sun J. Prognostic role of hormone receptors in ovarian cancer: a systematic reviewand metaanalysis. Int J Gynecol Cancer. 2013;23(1):2533. [Crossref] [Pubmed]

14. Hammond ME, Hayes DF, Dowsett M, Allred DC, Hagerty KL, Badve S, et al;American Society of Clinical Oncology; College of American Pathologists. American Society ofClinical Oncology/College of American Pathologists guideline recommendations forimmunohistochemical testing of estrogen and progesterone receptors in breast cancer(unabridged version). Arch Pathol Lab Med. 2010;134(7):e4872. [Pubmed]

15. Osborne CK, Yochmowitz MG, KnightWA 3rd McGuire WL. The value of estrogen and progesterone receptors in the treatment ofbreast cancer. Cancer. 1980;46(12 Suppl):2884-8. [Crossref]

16. Burton JL, Wells M. Recentadvances in the histopathology and molecular pathology of carcinoma of the endometrium. Histopathology. 1998;33(4):297-303. [Crossref] [Pubmed]

17. Kounelis S, Kapranos N, Kouri E,Coppola D, Papadaki H, Jones MW. Immunohistochemical profile of endometrial adenocarcinoma:a study of 61 cases and review of the literature. Mod Pathol. 2000;13(4):379-88. [Crossref] [Pubmed]

18. Gul AE, Keser SH, Barisik NO,Kandemir NO, Cakir C, Sensu S, et al. The relationship of cerb B 2 expression with estrogenreceptor and progesterone receptor and prognostic pa- rameters in endometrial carcinomas.Diagn Pathol. 2010;5:13. [Crossref] [Pubmed] [PMC]

19. Zhang $Y$, Zhao D, Gong $C$, Zhang F,He J, Zhang W, et al. Prognostic role of hormone receptors in endometrial cancer: asystematic review and meta-analysis. World J Surg Oncol. 2015;13:208. d [Crossref] [Pubmed] [PMC]

20. Creasman WT. Prognosticsignificance of hormone receptors in endometrial cancer. Cancer. 1993;71(4 Suppl):1467-70. [Crossref] [Pubmed]

21. Reijnen C, Visser NC, Kasius JC,Boll D, Geomini PM, $\mathrm{Ngo} \mathrm{H}$, et al. Improved preoperative risk stratification with CA-125 inlow-grade endometrial cancer: a multicenter prospective cohort study. J Gynecol Oncol.2019;30(5): e70. [Crossref] [Pubmed] [PMC]

22. Seebacher V, Grimm C, ReinthallerA, Heinze $G$, Tempfer $C$, Hefler $L$, et al. The value of serum albumin as a novel independentmarker for prognosis in patients with endometrial cancer. Eur J Obstet Gynecol Reprod Biol. 2013;171(1):101-6. [Crossref] [Pubmed] 